Atmos. Chem. Phys., 17, 13345-13359, 2017

https://doi.org/10.5194/acp-17-13345-2017

(C) Author(s) 2017. This work is distributed under

the Creative Commons Attribution 3.0 License.

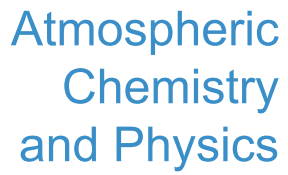

(c) (P)

\title{
Winds and temperatures of the Arctic middle atmosphere during January measured by Doppler lidar
}

\author{
Jens Hildebrand, Gerd Baumgarten, Jens Fiedler, and Franz-Josef Lübken \\ Leibniz-Institute of Atmospheric Physics at the Rostock University, Kühlungsborn, Germany \\ Correspondence to: Gerd Baumgarten (baumgarten@iap-kborn.de)
}

Received: 23 February 2017 - Discussion started: 20 March 2017

Revised: 22 September 2017 - Accepted: 25 September 2017 - Published: 10 November 2017

\begin{abstract}
We present an extensive data set of simultaneous temperature and wind measurements in the Arctic middle atmosphere. It consists of more than $300 \mathrm{~h}$ of Doppler Rayleigh lidar observations obtained during three January seasons (2012, 2014, and 2015) and covers the altitude range from $30 \mathrm{~km}$ up to about $85 \mathrm{~km}$. The data set reveals large yearto-year variations in monthly mean temperatures and winds, which in 2012 are affected by a sudden stratospheric warming. The temporal evolution of winds and temperatures after that warming are studied over a period of 2 weeks, showing an elevated stratopause and the reformation of the polar vortex. The monthly mean temperatures and winds are compared to data extracted from the Integrated Forecast System of the European Centre for Medium-Range Weather Forecasts (ECMWF) and the Horizontal Wind Model (HWM07). Lidar and ECMWF data show good agreement of mean zonal and meridional winds below $\approx 55 \mathrm{~km}$ altitude, but we also find mean temperature, zonal wind, and meridional wind differences of up to $20 \mathrm{~K}, 20 \mathrm{~m} \mathrm{~s}^{-1}$, and $5 \mathrm{~m} \mathrm{~s}^{-1}$, respectively. Differences between lidar observations and HWM07 data are up to $30 \mathrm{~m} \mathrm{~s}^{-1}$. From the fluctuations of temperatures and winds within single nights we extract the potential and kinetic gravity wave energy density (GWED) per unit mass. It shows that the kinetic GWED is typically 5 to 10 times larger than the potential GWED, the total GWED increases with altitude with a scale height of $\approx 16 \mathrm{~km}$. Since temporal fluctuations of winds and temperatures are underestimated in ECMWF, the total GWED is underestimated as well by a factor of 3-10 above $50 \mathrm{~km}$ altitude. Similarly, we estimate the energy density per unit mass for largescale waves (LWED) from the fluctuations of nightly mean temperatures and winds. The total LWED is roughly constant with altitude. The ratio of kinetic to potential LWED
\end{abstract}

varies with altitude over 2 orders of magnitude. LWEDs from ECMWF data show results similar to the lidar data. From the comparison of GWED and LWED, it follows that largescale waves carry about 2 to 5 times more energy than gravity waves.

\section{Introduction}

Winds in the middle atmosphere play an important role for atmospheric dynamics; e.g., filtering of gravity waves is controlled by the background wind field (e.g., Lindzen, 1981; Gill, 1982; Nappo, 2002). As these gravity waves transport energy and momentum over long distances, winds indirectly affect large-scale circulations (e.g., Geller, 1983; Holton, 1983). Therefore, wind measurements in the middle atmosphere with reasonable temporal and vertical resolution are of special interest (Meriwether and Gerrard, 2004; Drob et al., 2008). Not only do wind measurements provide additional information about atmospheric stability, together with temperature observations they also offer more sophisticated studies of gravity waves (e.g., Eckermann et al., 1995; Zink and Vincent, 2001; Placke et al., 2013; Bossert et al., 2014; Baumgarten et al., 2015) than studying gravity waves solely from temperature measurements (e.g., Chanin and Hauchecorne, 1981; Whiteway and Carswell, 1995; Alexander et al., 2011). In a recent study, Dörnbrack et al. (2017) point out that information about background wind is essential to correctly interpret ground-based gravity wave observations, specifically regarding identified phase lines and the vertical propagation direction. However, simultaneous wind and temperature measurements covering a wider altitude range of the middle atmosphere are rare (e.g., Goldberg et al., 
2004). The main reason is the technical challenge of wind measurements in these altitudes. Mesosphere-stratospheretroposphere (MST) and medium-frequency (MF) radars do not cover the altitude range between 20 and $60 \mathrm{~km}$ due to the absence of free electrons; whereas the altitude range of meteor radars starts at $\approx 80 \mathrm{~km}$ altitude (see, e.g., Fig. 1 in Baumgarten, 2010). Balloons only reach top altitudes of 30$40 \mathrm{~km}$. Meteorological rockets, equipped with chaff, falling spheres, or starutes, are able to measure winds in the entire middle atmosphere between about 20 and $100 \mathrm{~km}$ (e.g., Widdel, 1987, 1990; Schmidlin et al., 1991; Lübken and Müllemann, 2003; Müllemann and Lübken, 2005). Such rocket soundings yield a reasonable vertical resolution but are conducted only sporadically. Data from several campaigns at Arctic sites, which cover longer periods, have been published by, e.g., Meyer et al. (1987), Lübken and Müllemann (2003), and Müllemann and Lübken (2005). Microwave radiation is used to measure the Doppler shift of thermally excited molecules. This technique is used, e.g., by the Microwave Limb Sounder (MLS) instrument onboard the Aura satellite (Wu et al., 2008) and the ground-based WIRA instrument (Rüfenacht et al., 2012, 2014) and had been used by the SMILES instrument onboard the ISS (Baron et al., 2013). Another approach is to measure the Doppler shift of airglow lines. This was done by the High-Resolution Doppler Imager (HRDI) and the Wind Imaging Interferometer (WINDII) onboard the Upper Atmospheric Research Satellite (UARS) (Hays et al., 1993; Shepherd et al., 1993); the TIMED Doppler Interferometer (TIDI) onboard the Thermosphere-Ionosphere-Mesosphere Energetics and Dynamics (TIMED) satellite (Killeen et al., 2006) still employs this technique. The advanced E-Region Wind Interferometer (ERWIN II) (Kristoffersen et al., 2013) is a ground-based instrument which measures wind speeds by analyzing airglow; since it relies on three dedicated airglow emissions only, its height range is limited to layers between 87 and $97 \mathrm{~km}$ altitude. An indirect approach to estimate wind speeds from satellite observations is to retrieve geostrophic winds from geopotential heights at fixed pressure levels (e.g., Randel, 1987). The lidar technique allows us to derive wind speeds directly from measuring the Doppler shift of light backscattered at moving particles. Resolving the Doppler shift is technically challenging and wind lidars are therefore sophisticated instruments. While sodium resonance lidars yield wind speeds in the sodium layer between about 80 and $105 \mathrm{~km}$ altitude (e.g., Liu et al., 2002; She et al., 2002; Franke et al., 2005; Yuan et al., 2012), Rayleigh lidars mainly cover altitudes below $50 \mathrm{~km}$ (e.g., Tepley, 1994; Friedman et al., 1997; Souprayen et al., 1999; Huang et al., 2009; Xia et al., 2012). Reports about regular wind measurements by lidar are scarce: Tepley (1994) presents winds between 10 and $60 \mathrm{~km}$ altitude, derived during 43 nights at the tropical site Arecibo; Souprayen et al. (1999) derived horizontal winds during 170 nights in the altitude range $8-50 \mathrm{~km}$ at midlatitudes; regular observations of horizontal winds with sodium resonance lidars $(80-105 \mathrm{~km})$ were presented by Franke et al. (2005) and Yuan et al. (2012) for tropical and midlatitudes, respectively.

The Arctic Lidar Observatory for Middle Atmosphere Research (ALOMAR) Rayleigh/Mie/Raman (RMR) lidar is the only instrument that derives both horizontal wind components and temperature simultaneously from the upper stratosphere up to the mesosphere. In this study, we present horizontal winds and temperatures obtained by DoRIS, the Doppler Rayleigh Iodine Spectrometer of the ALOMAR RMR lidar, during the three January seasons of 2012, 2014, and 2015, in total more than $300 \mathrm{~h}$ of observations. They provide the most extensive data set of simultaneous wind and temperature measurements in the middle atmosphere and allow us to study the interannual variability in temperatures and winds, the temporal evolution on timescales of days, e.g., after the stratospheric warming in January 2012, and during single nights. This study also analyzes the representation of temperatures and winds by the Integrated Forecast System (IFS) of the European Centre for MediumRange Weather Forecasts (ECMWF) and the Horizontal Wind Model (HWM07) regarding the comparison to observational data. Subsequently, potential and kinetic energy densities of gravity waves and large-scale waves are calculated and analyzed.

\section{Instrument}

The ALOMAR RMR lidar $\left(69.3^{\circ} \mathrm{N}, 16.0^{\circ} \mathrm{E}\right)$ is a twin lidar with two identical transmitting lasers, two identical receiving telescopes and one detection system. It measures temperatures and aerosols in the middle atmosphere on a routine basis since 1997 (von Zahn et al., 2000; Schöch et al., 2008). Since 2009 the lidar has been measuring wind speeds as well, using DoRIS (Baumgarten, 2010). Detailed descriptions of the instrumental setup and the wind retrieval as well as initial results for the altitude range $30-85 \mathrm{~km}$ were presented by Baumgarten (2010), Hildebrand et al. (2012), and Lübken et al. (2016). Basically, the wind retrieval relies on measuring the Doppler shift of the backscattered light using iodine absorption spectroscopy; temperatures are retrieved by hydrostatic integration of altitude profiles of relative air density (Kent and Wright, 1970; Hauchecorne and Chanin, 1980). The two individually derived temperature profiles for both lasers/telescopes are averaged to one temperature profile; this reduces the measurement uncertainty, but the amplitudes of gravity waves are not affected significantly (since the distance of both sounding volumes is much shorter than typical horizontal wavelengths of the inertia gravity waves which are most prominent in the $1 \mathrm{~h}$ averaged profiles: $40 \mathrm{~km}$ distance at $80 \mathrm{~km}$ altitude compared to wavelengths of several hundred kilometers, (e.g., Baumgarten et al., 2015)). 

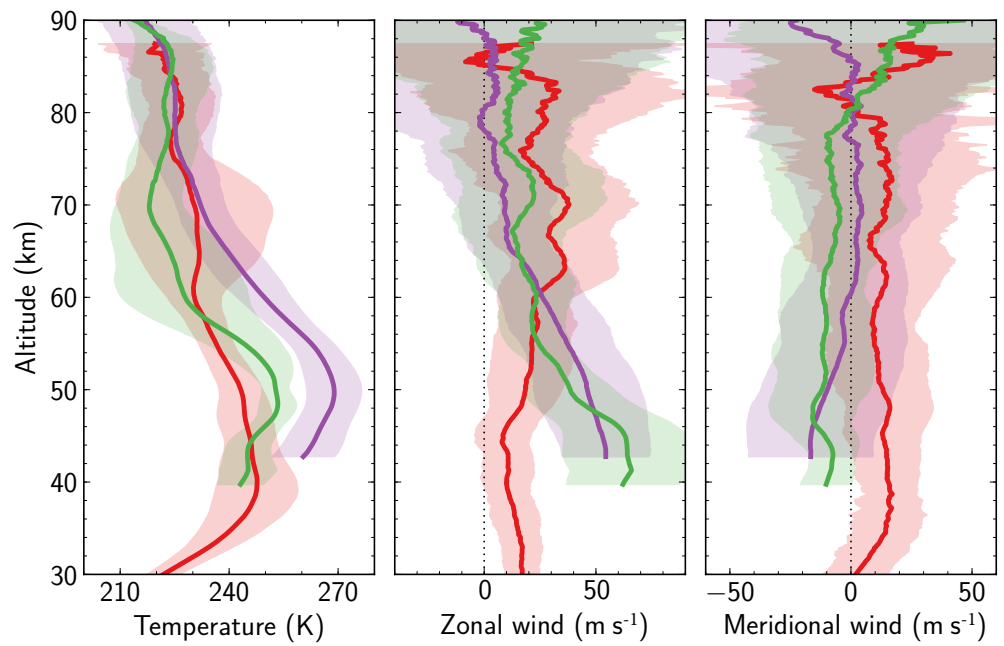

Figure 1. January mean temperatures and horizontal winds derived by lidar for the years 2012 (red), 2014 (purple), and 2015 (green). Shaded areas represent the corresponding standard deviations (SDs).

\section{Data and processing}

\subsection{Data}

The data set used for this study was acquired during nights in January 2012, 2014, and 2015. January 2013 is excluded since there exist only about $10 \mathrm{~h}$ of nighttime horizontal wind observations. The data were integrated over $1 \mathrm{~h}$. The vertical resolution is $150 \mathrm{~m}$, but data were smoothed with a running window with a size of $3 \mathrm{~km}$. Typical uncertainties are $0.5 \mathrm{~K}$ and $3 \mathrm{~m} \mathrm{~s}^{-1}$ at $50 \mathrm{~km}$ altitude, but they increase with altitude (due to less received backscattered light from higher altitudes, mainly due to decreasing air density). The retrieved temperature and wind speed profiles considered in this study are limited to measurement uncertainties of $\Delta T \leq 5 \mathrm{~K}$ and $\Delta u=\Delta v \leq 20 \mathrm{~m} \mathrm{~s}^{-1}$, respectively.

Due to technical issues the lower altitude limit in January 2014 and January 2015 is about $40 \mathrm{~km}$ instead of $30 \mathrm{~km}$.

As lidar operations depend on weather conditions, the observations are unequally distributed over the years: $65 \mathrm{~h}$ during 7 nights between 19 and 30 January 2012, $170 \mathrm{~h}$ during 16 nights between 10 and 31 January 2014 , and $78 \mathrm{~h}$ during 5 nights between 19 and 24 January 2015. Table 1 lists the nights and the respective duration of the lidar observations. Note that although the sampling is quite sparse in January 2012 and 2015, these are the only available simultaneous wind and temperature observations in the Arctic stratosphere and mesosphere. For the analysis of wave phenomena in Sects. 4.4 and 4.5, we restrict the data set to nights with observations of at least $10 \mathrm{~h}$; this reduces the number of observations taken into account to two-thirds of the entire data set, but the fraction of data taken into account is reduced by only $1 / 10$. Table 2 gives an overview of the observations taken into account for analyses based on all nights and long observations only.
Table 1. List of lidar observations taken into account in this study.

\begin{tabular}{lr}
\hline Night & 1 h profiles \\
\hline 19/20 Jan 2012 & 2 \\
21/22 Jan 2012 & 15 \\
22/23 Jan 2012 & 13 \\
23/24 Jan 2012 & 2 \\
24/25 Jan 2012 & 3 \\
28/29 Jan 2012 & 12 \\
29/30 Jan 2012 & 15 \\
1/2 Feb 2012 & 1 \\
3/4 Feb 2012 & 2 \\
\hline 10/11 Jan 2014 & 14 \\
11/12 Jan 2014 & 17 \\
14/15 Jan 2014 & 11 \\
15/16 Jan 2014 & 17 \\
17/18 Jan 2014 & 11 \\
18/19 Jan 2014 & 17 \\
19/20 Jan 2014 & 13 \\
20/21 Jan 2014 & 11 \\
21/22 Jan 2014 & 5 \\
22/23 Jan 2014 & 12 \\
23/24 Jan 2014 & 1 \\
24/25 Jan 2014 & 12 \\
26/27 Jan 2014 & 10 \\
27/28 Jan 2014 & 5 \\
29/30 Jan 2014 & 7 \\
30/31 Jan 2014 & 7 \\
\hline 19/20 Jan 2015 & 16 \\
20/21 Jan 2015 & 16 \\
21/22 Jan 2015 & 13 \\
22/23 Jan 2015 & 16 \\
23/24 Jan 2015 & 17 \\
\hline
\end{tabular}


Table 2. Number of nights and $1 \mathrm{~h}$ profiles taken into account for figures showing monthly mean data.

\begin{tabular}{rrr|rr}
\hline & \multicolumn{2}{c|}{ All observations } & \multicolumn{2}{c}{ Long observations $(\geq 10 \mathrm{~h})$} \\
\cline { 2 - 5 } Year & Nights & 1 h profiles & Nights & 1 h profiles \\
\hline 2012 & 7 & 62 & 4 & 55 \\
2014 & 16 & 170 & 11 & 145 \\
2015 & 5 & 78 & 5 & $76^{*}$ \\
\hline
\end{tabular}

* The observations in the night $21 / 22$ January 2015 consist of two parts of 11 and $2 \mathrm{~h}$, respectively, separated by a gap of $5 \mathrm{~h}$.

Additionally, model data are used for the location of ALOMAR:

- The European Centre for Medium-Range Weather Forecasts provides the IFS. We extracted data with horizontal resolution $\mathrm{T} 1279$ at the location $69.28^{\circ} \mathrm{N}$, $16.01^{\circ} \mathrm{E}$ (the data are available with horizontal resolution of $0.25^{\circ}$; we interpolated these horizontally at pressure levels to our location). We use data from the forecast system with a temporal resolution of $1 \mathrm{~h}$; hence, lidar data and ECMWF data have the same temporal sampling. Profiles between midnight and noon were taken from the model run initialized at 00:00 UTC; profiles between noon and midnight were taken from the 12:00 UTC run. For January 2012 we used cycle Cy37r3, and for January 2014 and 2015 we used cycle Cy40r1. Both cycles differ, amongst other things, in their vertical resolution, especially at higher altitudes: Cy37r3 has 91 model levels; Cy40r1 has 137 model levels. For each single $1 \mathrm{~h}$ profile the pressure coordinate is converted into geometric altitude; the profile is then interpolated to the vertical resolution of the lidar data.

- The HWM07 is an empirical model that accumulates data from different instruments obtained over 50 years (Drob et al., 2008). Therefore, the model does not contain any year-to-year variation but has more of a character of a climatology. We extracted data on an hourly basis (corresponding to the temporal sampling of the lidar) for the location $69.3^{\circ} \mathrm{N}, 16.0^{\circ} \mathrm{E}$.

\subsection{Gravity wave energy density}

We used the following equations (e.g., Geller and Gong, 2010) to derive potential and kinetic gravity wave energy density (GWED) per unit mass from temperature and wind speed fluctuations $\left(T^{\prime}, u^{\prime}\right.$, and $v^{\prime}$, respectively):

$E_{\mathrm{pot}}=\frac{1}{2} \frac{g^{2}}{N^{2}}\left(\frac{T^{\prime}}{\bar{T}}\right)^{2}$

and

$E_{\text {kin }}=\frac{1}{2}\left(u^{\prime 2}+v^{\prime 2}\right)$,

with $g$ as gravitational acceleration, $N$ as the Brunt-Väisälä frequency, and $\bar{T}$ as background temperature. The fluctuations are derived by subtracting the corresponding nightly mean profile. As stated by Ehard et al. (2015), applying this method might include tidal signatures in the resulting gravity wave energy densities; furthermore, the resolved gravity wave (GW) spectrum depends on the length of an observation, which hinders comparison of GWEDs. Although Ehard et al. (2015) proposed applying a Butterworth filter to extract GWs, we use the nightly mean method since we tested different approaches for background estimation with our lidar data and found no significant differences in the resulting GWEDs. To accommodate the mentioned drawbacks of the nightly mean method, we apply the following procedure: we take only measurements with at least $10 \mathrm{~h}$ duration into account (since the nightly mean profiles of shorter measurements would include wave-like features); within one night we then select the first ten $1 \mathrm{~h}$ profiles to calculate GWEDs for this time span (therefore, the covered GW spectrum is relatively wide and constant for all observations, although it might contain some short-scale tidal components); we shift the $10 \mathrm{~h}$ window by $1 \mathrm{~h}$ and repeat the GWED calculation as often as the window fits into the observation period of that night (therefore, different phases of possibly included tides are sampled); finally, we calculate the mean and the standard deviation (SD) of all the GWED profiles of one night (therefore, we can estimate the GWED variability during single nights).

\section{Results}

\subsection{January variability}

For a first descriptive presentation of the data set, Fig. 1 shows mean altitude profiles of temperatures and horizontal winds for Januaries 2012, 2014, and 2015. It is evident that the mean profiles for the 3 years differ remarkably. While in 2012 highest temperatures of $245 \mathrm{~K}$ occur at $38 \mathrm{~km}$ altitude, highest temperatures in 2014 are $270 \mathrm{~K}$ and occur at $50 \mathrm{~km}$ altitude; the temperatures in 2012 and 2015 show enhanced variability around 70 and $60 \mathrm{~km}$ altitude, respectively, but there is no such enhanced variability in 2014. The strength of the eastward zonal winds varies, too: in 2014 and 2015, highest wind speeds of $50-70 \mathrm{~m} \mathrm{~s}^{-1}$ occur around $45 \mathrm{~km}$ altitude, while in 2012 the zonal wind is weak at this height, and the highest zonal wind speeds occur between 62 and $72 \mathrm{~km}$, 

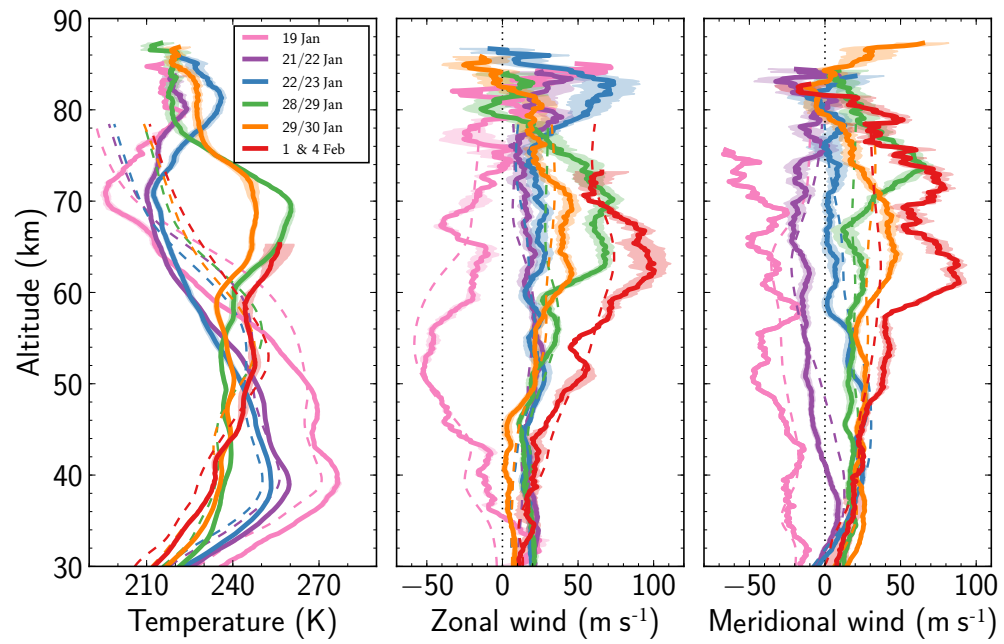

Figure 2. Temporal evolution of temperature and horizontal winds during January and early February 2012 after a minor SSW. The profiles are averages of all $1 \mathrm{~h}$ profiles of the relevant night(s). Solid lines and shaded areas: lidar data and corresponding SDs; dashed lines: ECMWF data with same temporal sampling.

with enhanced variability. Mean meridional winds even have different directions in different years: in 2012, the direction is mainly northward; in 2014, there is no predominant direction; and in 2015, it is mainly southward.

Besides these noticeable year-to-year variations, we find large variability within the Januaries of the different years. The SDs of temperature data at 50 and $70 \mathrm{~km}$ altitude are 6 and $21 \mathrm{~K}$ in January 2012, 8 and $7 \mathrm{~K}$ in January 2014, and 4 and $9 \mathrm{~K}$ in January 2015; the increased SD of $18 \mathrm{~K}$ at $60 \mathrm{~km}$ altitude in January 2015 is noteworthy. The SDs of zonal and meridional wind data are of nearly the same size $\left( \pm 2 \mathrm{~m} \mathrm{~s}^{-1}\right)$ : at $50 \mathrm{~km}$ and $70 \mathrm{~km}$ altitude, respectively, they are 18 and $29 \mathrm{~m} \mathrm{~s}^{-1}$ in January 2012, 24 and $26 \mathrm{~m} \mathrm{~s}^{-1}$ in January 2014, and 20 and $30 \mathrm{~m} \mathrm{~s}^{-1}$ in January 2015 .

Concluding from the remarkable year-to-year variations and variabilities within Januaries of different years: the polar middle atmosphere in January cannot be described by one single "winter state", and it is not appropriate to infer a general statement or even a climatology from observations of only a few seasons. To investigate the variations in one single month an example is shown in the next section.

\subsection{Elevated stratopause and polar vortex reformation after minor SSW in January 2012}

During winters, variability in the polar middle atmosphere is mainly caused by planetary waves and sudden stratospheric warmings (SSWs): depending on their type and strength, the polar vortex may be weakened, displaced, or even split; warmer air from midlatitudes may intrude into the polar region (e.g., Matsuno, 1971; Labitzke, 1972). The number of SSWs during one season and the time at which they appear vary from year to year (e.g., Labitzke and Kunze, 2012).
Around 15 January 2012 a minor SSW, which was a vortex displacement event, occurred (Chandran et al., 2013b; Matthias et al., 2013). The ALOMAR RMR lidar took data during the following days and weeks, i.e., in the aftermath of the SSW. Figure 2 shows the temporal evolution of temperature and zonal and meridional wind after the SSW, starting on 19 January until 4 February. Except for the doublestratopause structure, the temperature profiles from 19 January do not look unusual; the temperature increase between 70 and $80 \mathrm{~km}$ altitude indicates a mesospheric inversion layer, whose investigation is, however, beyond the scope of this study. In contrast, the westward zonal winds are exceptional for winter, which is probably a result of the vortex displacement. The strength and relative position of the polar vortex can be inferred from the potential vorticity: Rex et al. (1998) define $36 \mathrm{PVU}$ at the $475 \mathrm{~K}$ potential temperature level as the edge of the polar vortex. Based on this definition and using potential vorticity and potential temperature from ECMWF data, we find that ALOMAR is situated inside the polar vortex during that night. It has to be kept in mind that the polar vortex might bend and twist, and therefore the vortex location as defined at $475 \mathrm{~K}(\approx 19 \mathrm{~km}$ altitude) may not always represent the situation in the upper strato- and mesosphere. Only a few days later (21/22 and $22 / 23$ January) the stratopause was $\approx 15-20 \mathrm{~K}$ colder and the upper mesosphere around $70 \mathrm{~km}$ altitude was $\approx 15-20 \mathrm{~K}$ warmer; zonal winds were weakly eastward over the entire altitude range, and meridional winds developed from weakly southward to weakly northward with only small variations in altitude. On the first of these two nights the polar vortex edge was above ALOMAR, while on the second night ALOMAR was situated outside the vortex. Baumgarten et al. (2015) show time-altitude sections of temperature and wind data of this period, which exhibit very pronounced gravity 
wave structures. During the following week, the thermal and dynamic structure over ALOMAR changed remarkably: on 28/29 and 29/30 January, the temperature maximum around $40 \mathrm{~km}$ altitude vanished and the highest temperatures shifted upward to around $70 \mathrm{~km}$ altitude, at roughly the same altitude where maxima of zonal and meridional wind occurred. ALOMAR was again situated inside the polar vortex. During the beginning of February, the maxima in temperature, zonal wind, and meridional wind intensified and descended further. These phenomena are closely connected to the preceding SSW: they are referred to as elevated stratopause and reformation of the polar vortex, which sometimes occur after stratospheric warmings (e.g., Labitzke, 1972; Manney et al., 2009). In contrast to this work, the two studies by Labitzke et al. and Manney et al. analyzed vortex split events with a complete breakdown of the polar vortex.

Concluding, the minor SSW of 2012 is peculiar: it is followed by an elevated stratopause event, although it is neither a major warming nor a vortex split event. Thus, this observation is evidence that elevated stratopause events can occur even after minor SSW, as previously stated by de la Torre et al. (2012) and Chandran et al. (2013a). Although the basic mechanisms of elevated stratopauses and the polar vortex reformation are known (e.g., Tomikawa et al., 2012) and temperatures and zonal mean zonal winds were derived previously (winds only indirectly from geopotential-height observations by satellites (e.g., Manney et al., 2009)), this is the first time to our knowledge that an elevated stratopause together with the reformation of the polar vortex have been observed with a direct temperature and wind measurement technique. These unique observations reveal features which are not represented in ECMWF data, which highlights the need for observations of such peculiar events to broaden the data basis against which models can be compared to test their fidelity. The differences, which are present in temperature and wind data as well, highlight the importance of local observations with adequate spatial and temporal resolution and will be discussed in detail in the following section.

\subsection{Comparison to models}

Figure 2 includes data extracted from ECMWF. Especially above $50 \mathrm{~km}$ altitude the comparison between lidar and ECMWF is dissatisfying, particularly for the end of January and beginning of February: the elevated stratopause and the reformation of the polar vortex are not captured in ECMWF. This leads to differences of up to $40 \mathrm{~K}$ and $20 \mathrm{~m} \mathrm{~s}^{-1}$, respectively. One explanation for the poor comparison might be that this period was affected by an SSW. Therefore, we compare lidar data with ECMWF and HWM07 data for the whole data set, which is shown in Fig. 3: it depicts the same lidar profiles as Fig. 1 and mean profiles taken from ECMWF for January 2012 (Fig. 3a), January 2014 (Fig. 3b), and January 2015 (Fig. 3c), and data cumulated over all three seasons, including HWM07 (Fig. 3d). Note that all three data sets have the same temporal sampling. The SD is calculated as the deviation of all $1 \mathrm{~h}$ profiles of 1 month from the monthly mean profile, which is calculated from these $1 \mathrm{~h}$ profiles.

We first concentrate on HWM07 data (Fig. 3d, winds only). Although HWM07 is more like a climatology without any year-to-year variation, some studies use it as representation of mean or background wind fields, even for single case studies, (e.g., Assink et al., 2012; Hedlin and Walker, 2012; Fee et al., 2013). However, HWM07 describes the actual winds inadequately: the zonal wind is too weak in the upper stratosphere (compared to ECMWF) and too strong in the upper mesosphere (compared to lidar), with differences up to $20 \mathrm{~m} \mathrm{~s}^{-1}$; in between, mean zonal wind matches quite well.

HWM07's meridional wind is northward in the entire altitude range, while the mean observed meridional wind is weakly southward below $60 \mathrm{~km}$ altitude and weakly northward above; differences are on the order of $30 \mathrm{~m} \mathrm{~s}^{-1}$. It is remarkable that the meridional wind in HWM07 is not only of a different magnitude than the observed winds but also of a different direction. The temporal variability (indicated by the SD) is much smaller than for the lidar data. One reason for this discrepancy, aside from the missing year-to-year variations in HWM07, is the limited number of observations taken into account in HWM07 for this location and altitude range (see Table 1 in Drob et al. (2008)).

Comparison with ECMWF data: the data of 2014 and 2015 were not affected by SSWs, but still the temperature comparison between lidar and ECMWF is not good: the stratopause is too cold (up to $10 \mathrm{~K}$ ) and too low (up to $4 \mathrm{~km}$ ) in ECMWF; at higher altitudes temperatures from ECMWF are much too low, namely up to $25 \mathrm{~K}$. This can also be seen in Fig. 4a, which shows altitude profiles of the mean of the hourly differences $\left(\Delta x=\frac{1}{N} \sum\left(x_{\mathrm{ECMWF}}-x_{\text {lidar }}\right)\right)$, including the corresponding SD and the standard error of the mean for the lidar data. Regarding zonal winds, the comparison between ECMWF and lidar is nonuniform for the 3 years: in 2012 and 2014 it is very good below $60 \mathrm{~km}$ altitude with mean differences of $2 \mathrm{~m} \mathrm{~s}^{-1}$ or less, while above $60 \mathrm{~km}$ altitude mean differences are up to 20 and $15 \mathrm{~m} \mathrm{~s}^{-1}$, respectively; in 2015 mean differences between 10 and $20 \mathrm{~m} \mathrm{~s}^{-1}$ occur throughout the altitude range of $45-70 \mathrm{~km}$. For meridional winds the comparison is much better: mean differences are mostly smaller than or around $5 \mathrm{~m} \mathrm{~s}^{-1}$ only, hence on the same order as the standard error of the mean of the lidar data.

Similar results concerning ECMWF temperatures in the middle and upper mesosphere were reported by, e.g., Le Pichon et al. (2015). They state that the wave-like pattern of the difference profile might be caused by a quasi-stationary planetary wave structure. A study by Rüfenacht et al. (2014) applying wind radiometry found good agreement of observed winds and ECMWF wind data in the stratosphere but deviations in the mesosphere up to $50 \%$ of the true wind speeds. 
(a)

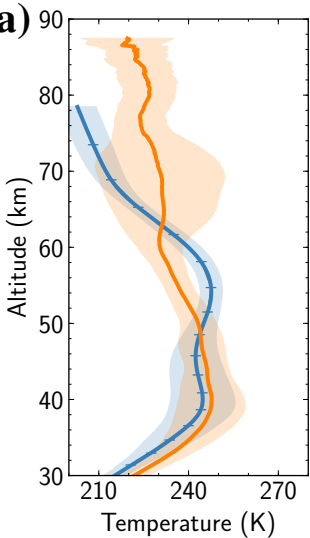

(c)

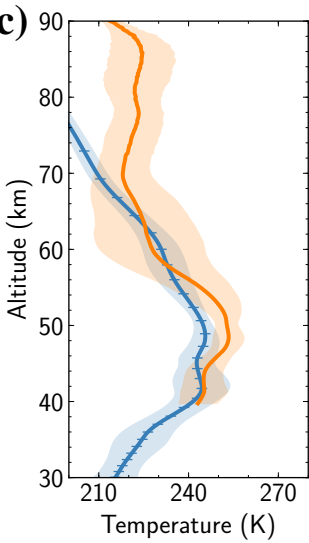

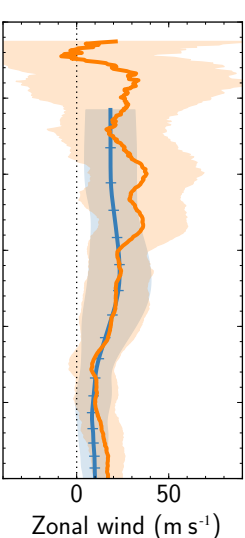
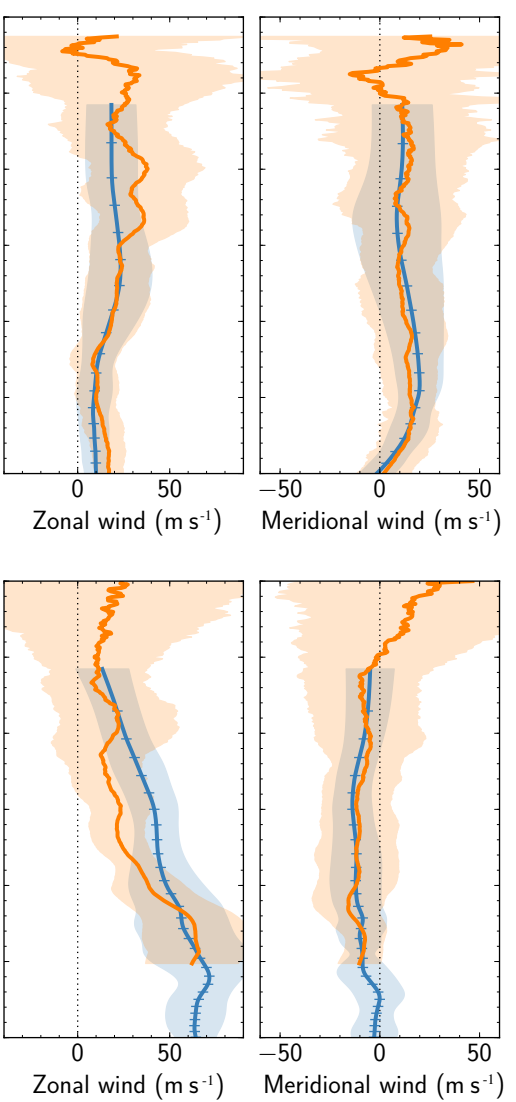

(b)
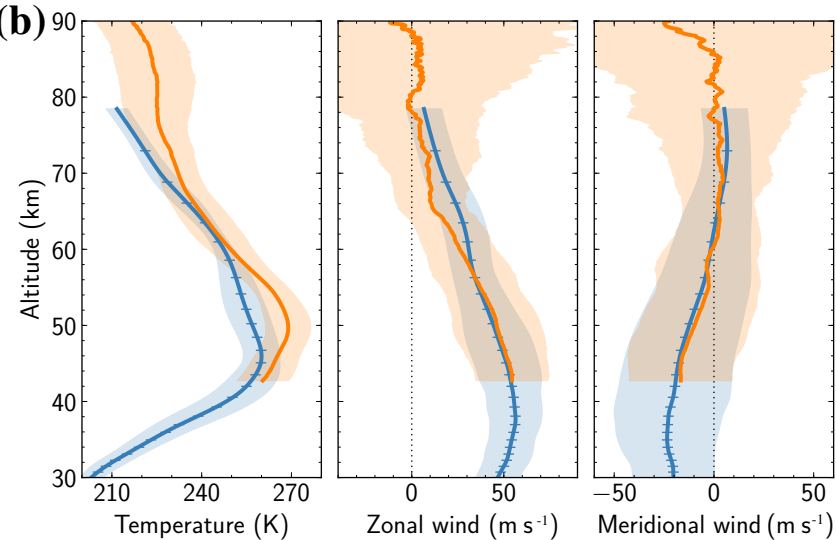

(d)
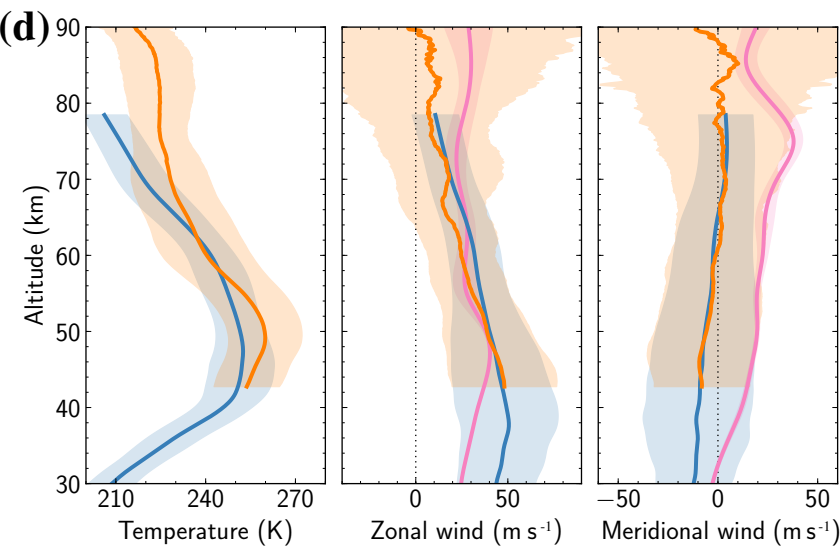

Figure 3. January mean temperatures and horizontal winds for the years 2012 (a), 2014 (b), and 2015 (c) and cumulated data (d). ALOMAR RMR lidar (orange); ECMWF (blue); HWM07 (rose). Shaded areas represent the corresponding SDs. The horizontal bars mark the model levels of ECMWF data for one sample profile in each season. The ECMWF cycles used are Cy37r3 for 2012 and Cy40r1 for 2014 and 2015.

Please note that the ECMWF IFS cycles used in these studies differ from the ones used in this study.

Figure $4 \mathrm{~b}$ shows distributions of differences between ECMWF and lidar on an hourly basis for different altitude ranges. The distributions of differences are broader for higher altitudes; some distributions are not symmetrical, indicating systematic under- or overestimations for the relevant measure. This is especially true for temperatures and zonal winds above $50 \mathrm{~km}$ altitude but does not appear for meridional winds in the entire altitude range covered.

This leads to studying the comparison of lidar and ECMWF data on shorter timescales: Fig. 5 shows all $1 \mathrm{~h}$ profiles of temperature, zonal, and meridional wind speed, derived by lidar during the night of 20/21 January 2015 (between 14:40 and 07:30 UTC) and extracted from ECMWF corresponding to the temporal and altitude sampling of the lidar. Despite the differences between the mean lidar and ECMWF profiles, it is obvious that the lidar data show a larger variability in altitude and time. These differences on smaller scales are the reason for the width of the distribution of differences shown in Fig. 4b. Despite the differences of single $1 \mathrm{~h}$ profiles or nightly mean profiles in princi- ple, the smaller temporal and vertical variability in ECMWF data might indicate that the amount of energy and momentum which is transported by waves is underestimated in ECMWF, which might cause part of the discrepancies of the mean state as shown in Fig. 4a.

To study the comparison of the variability in each data set in more detail, the dashed lines in Fig. 5 show the root mean square (rms) of the fluctuations of the $1 \mathrm{~h}$ profiles, hence their variability. The rms of the lidar data increases with altitude, indicating an increase in the amplitudes of the temperature and wind fluctuations (note that the rms increases faster and is always larger than the mean measurement uncertainty of the lidar data). This is what is expected for the effect of gravity waves, as their amplitudes increase with altitude due to the decreasing air density. In contrast, the rms profiles of the ECMWF data do not show a general increase with altitude and in a large part of the altitude range the rms of the ECMWF data is smaller than the rms of the lidar data. This is also true for the whole data set, as can be seen in Fig. 4c: for each night with at least $10 \mathrm{~h}$ of data, the rms of the lidar data and the rms of the ECMWF data are calculated. Then the monthly average of the ratio of both is calculated and 
(a)
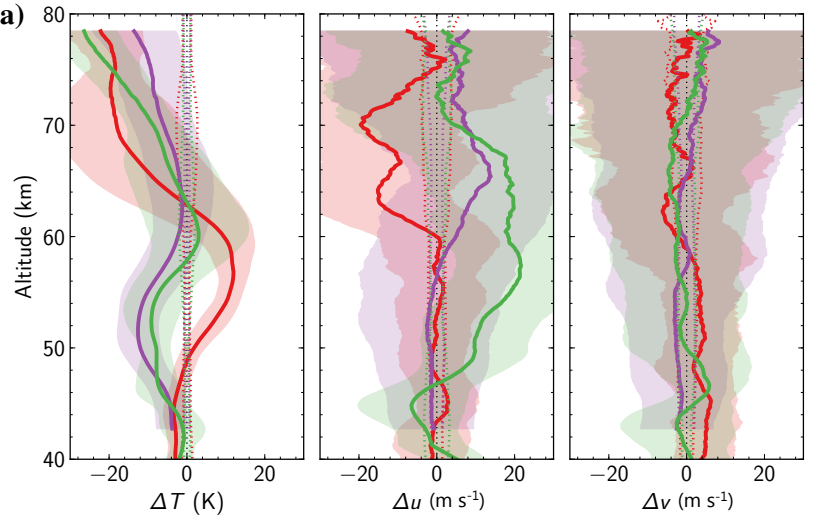

(b)
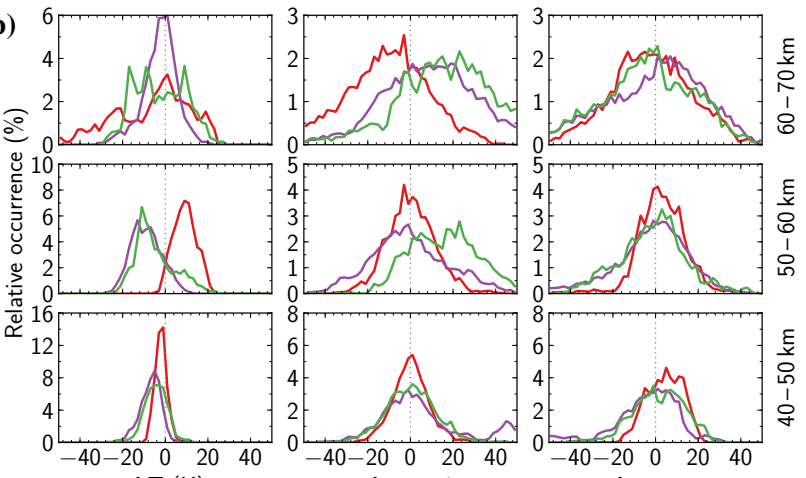

$\Delta T(\mathrm{~K})$

(c)

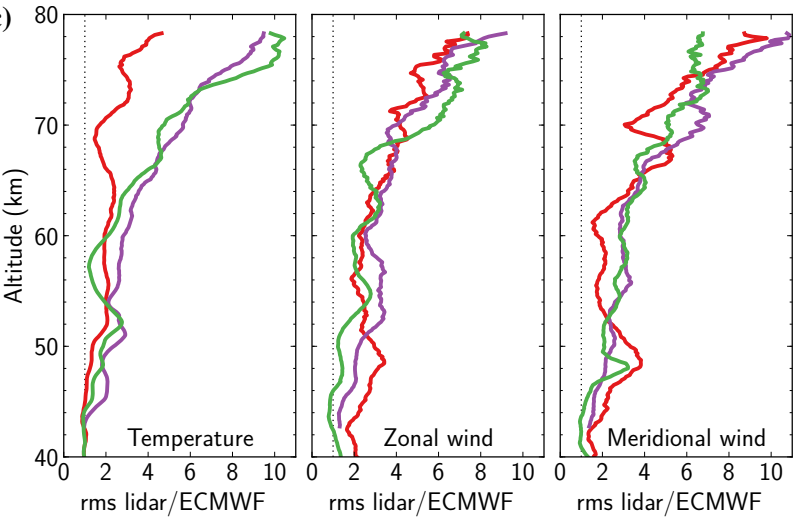

Figure 4. Differences between lidar data and ECMWF data for January 2012 (red), January 2014 (purple), and January 2015 (green); the ECMWF cycles used are Cy37r3 for 2012 and Cy40r1 for 2014 and 2015. (a) Mean difference $\frac{1}{N} \Sigma\left(x_{\mathrm{ECMWF}}-x_{\text {lidar }}\right)$; shading represents the corresponding SDs; dotted lines depict the standard error of the mean of the lidar data. (b) Distribution of differences $x_{\mathrm{ECMWF}}-x_{\text {lidar }}$ on an hourly basis for different altitude ranges. (c) Mean ratio of rms of lidar and ECMWF data. See Table 2 for an overview of the number of $1 \mathrm{~h}$ profiles taken into account.

drawn. In general, the higher the altitude, the worse the actual variability represented in ECMWF is. Above $\approx 75 \mathrm{~km}$ altitude the ECMWF variability is only $1 / 10$ of the variability observed by lidar; one exception is the temperature in January 2012, when the ECMWF variability even at high altitudes is about one-third of the lidar variability. Similar

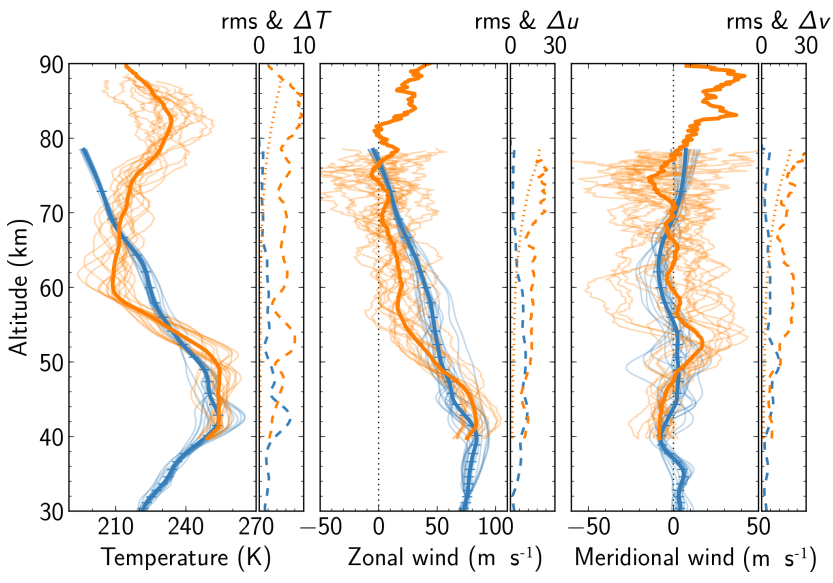

Figure 5. Temperature and horizontal winds for the night of 20/21 January 2015; lidar (orange); ECMWF (blue). Thin lines denote $1 \mathrm{~h}$ profiles; thick lines denote the nightly mean profiles, the horizontal bars mark the model levels of ECMWF data for one sample profile; dashed and dotted lines show the rms and the mean measurement uncertainty of the $1 \mathrm{~h}$ profiles, respectively.

results regarding the height-dependent underestimation of gravity wave amplitudes were also reported by Schroeder et al. (2009). From a comparison of model data with global satellite observations they infer that temperature amplitudes in ECMWF are underestimated by a factor of 2 at $28 \mathrm{~km}$ altitude and more than 5 times above $40 \mathrm{~km}$ altitude. The reason for the underestimation of the variability at higher altitudes is likely damping mechanisms that are applied in the ECMWF model; an extensive overview of several such approaches is given by Jablonowski and Williamson (2011).

Concluding, ECMWF and especially HWM07 do not represent the thermal and dynamic state of the middle atmosphere sufficiently, neither regarding January mean profiles nor the variability within individual nights, which are underestimated in ECMWF data. This distinct underestimation of the temporal variability in temperatures and winds affects the calculated energy budget of gravity waves, which are the main source of fluctuations on the scale of a few hours. Resulting gravity wave energy densities are discussed in the next section.

\subsection{Gravity wave energy density}

The combination of simultaneous wind and temperature measurements allows us to perform wave studies in more detail. For instance, the energy budget of gravity waves consists of potential and kinetic gravity wave energy. While the former depends on the temperature fluctuations, the latter is based on the wind speed fluctuations.

As an example, Fig. 6a shows vertical profiles of potential and kinetic GWED for the night of 20/21 January 2015. Except at around 47 and $52 \mathrm{~km}$ altitude, the kinetic GWED is larger than the potential GWED, mostly by 


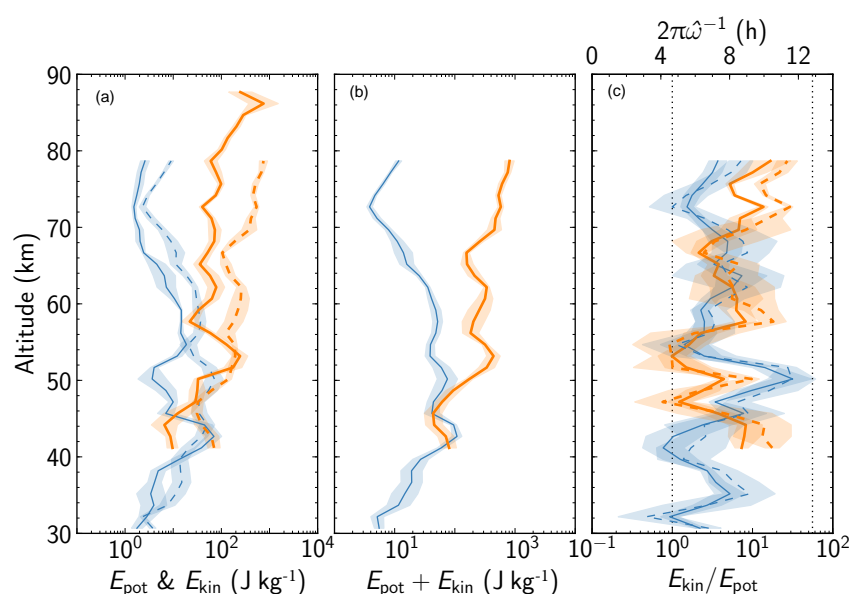

Figure 6. Gravity wave energy densities per unit mass and the intrinsic period $\left(2 \pi \hat{\omega}^{-1}\right)$ a monochromatic gravity wave with the given kinetic-to-potential GWED ratio would have, for the night of 20/21 January 2015; lidar (orange); ECMWF (blue). Panel (a): potential (solid) and kinetic (dashed) GWED. Panel (b): total GWED. Panel (c): kinetic-to-potential GWED (solid) and $2 \pi \hat{\omega}^{-1}$ (dashed); the dotted vertical lines denote unity and $2 \pi f^{-1}$, respectively. Shading represents the corresponding SD.

4 to 5 times (shown in Fig. 6c). As expected from Eq. (1) the potential GWED shows minima and maxima at the same altitudes as the minima and maxima of the temperature fluctuations (cf. Fig. 5), while the kinetic GWED correlates to features of zonal and meridional wind fluctuations (e.g., the minimum of kinetic GWED at $67 \mathrm{~km}$ altitude).

Figure $6 \mathrm{~b}$ shows the total GWED. Between 47 and $53 \mathrm{~km}$ altitude and above $67 \mathrm{~km}$, the total GWED increases with altitude.

In between is a layer of nearly constant total GWED where the kinetic GWED is roughly constant and the potential GWED slightly decreases. A possible reason might be the near-adiabatic temperature gradient between 50 and $60 \mathrm{~km}$ altitude (some profiles show gradients of $\approx-7 \mathrm{~K} \mathrm{~km}^{-1}$ ), which hinders the upward propagation of gravity waves.

Figure $6 \mathrm{c}$ shows the ratio of kinetic to potential GWED and the intrinsic period $2 \pi \hat{\omega}^{-1}$ that a monochromatic lowor medium-frequency gravity wave with the given $E_{\text {pot }}$ and $E_{\text {kin }}$ would have (Geller and Gong, 2010):

$\hat{\omega}= \pm f \sqrt{\frac{E_{\mathrm{kin}} / E_{\mathrm{pot}}+1}{E_{\mathrm{kin}} / E_{\mathrm{pot}}-1}}$,

with the Coriolis parameter $f=2 \Omega \sin \phi(\Omega$ : angular speed of Earth's rotation; $\phi$ : latitude of observation). We have shown earlier that at times of quasi-monochromatic waves the intrinsic periods calculated from the energy ratios agree to the results of the hodograph method (Baumgarten et al., 2015). While the hodograph method can only be applied in the case of a quasi-monochromatic wave - because it would otherwise be hard or even impossible to identify an ellipse from the zonal and meridional wind fluctuations -, the energy ratio method is applicable also to wind and temperature fluctuations caused by various waves, keeping in mind that the derived $2 \pi \hat{\omega}^{-1}$ is not the intrinsic period of a certain wave. However, the method has been applied previously to data sets probably affected by the superposition of various gravity waves (e.g., Geller and Gong, 2010; Baumgarten et al., 2015). Note that since temperature and horizontal wind fluctuations are more sensitive to long-period gravity waves than to short-period gravity waves, the energy ratio method is biased toward long-period gravity waves, as stated by Lane et al. (2003) and evaluated by Geller and Gong (2010, their App. A). Nevertheless, due to the temporal integration of the data presented here, short-period gravity waves are discarded anyway. The retrieved $2 \pi \hat{\omega}^{-1}$ is larger than $8 \mathrm{~h}$ in most parts; highest values are about $11 \mathrm{~h}$, reasonably smaller than the upper limit of $2 \pi f^{-1}=12.82 \mathrm{~h}$. According to the relationship for the group velocity vector (e.g., Fritts and Alexander, 2003)

$$
\begin{aligned}
& \left(c_{\mathrm{g} x}, c_{\mathrm{g} y}, c_{\mathrm{g} z}\right)=(\bar{u}, \bar{v}, 0) \\
& +\frac{\left[k\left(N^{2}-\hat{\omega}^{2}\right), l\left(N^{2}-\hat{\omega}^{2}\right),-m\left(\hat{\omega}^{2}-f^{2}\right)\right]}{\hat{\omega}\left(k^{2}+l^{2}+m^{2}+\frac{1}{4 H^{2}}\right)},
\end{aligned}
$$

with $k, l, m$ as zonal, meridional, and vertical wave number, respectively; this indicates a more horizontal wave propagation, as $\hat{\omega}^{2}-f^{2} \rightarrow 0$ (and $\hat{\omega}^{2} \ll N^{2}$ ). The two pronounced minima of $2 \pi \hat{\omega}^{-1}$ around 46 and $53 \mathrm{~km}$ altitude are caused by the equality of potential and kinetic GWED; wind fluctuations are quite low at these altitudes, while the temperature fluctuations are quite large. This then indicates waves which propagate more vertically, as the weight of $N^{2}-\hat{\omega}^{2}$ in Eq. (3) decreases and the weight of $\hat{\omega}^{2}-f^{2}$ increases. The different vertical-to-horizontal propagation conditions at 46 and $53 \mathrm{~km}$ compared to the remaining altitude ranges may have different causes: (1) different origin of the waves; (2) changing background propagation conditions, i.e., filtering/Doppler shift due to the strong zonal wind shear at these altitudes, reducing wind speeds from 80 to $20 \mathrm{~m} \mathrm{~s}^{-1}$. A clear distinction between these possible explanations is not possible: while the second option is clearly visible in Fig. 5 (large temperature gradient and strong wind shear), the first option can not be excluded. However, a detailed investigation of propagation conditions is beyond the scope of this study.

Figure 6 includes also GWEDs and the $2 \pi \hat{\omega}^{-1}$ derived from ECMWF data for the same time period. In the lower part (up to $\approx 50 \mathrm{~km}$ altitude), the GWEDs are comparable to the lidar data. Above, the total GWED derived from ECMWF data decreases with altitude. Therefore, at $70 \mathrm{~km}$ altitude the GWEDs derived from ECMWF data are nearly 2 orders of magnitude too small. The kinetic-to-potential GWED ratio is on the same order as the GWED ratio derived by lidar, although the shapes differ, yielding differing profiles of $2 \pi \hat{\omega}^{-1}$. 
Are these results special or typical? Figure 7 shows mean GWEDs for January 2012, 2014, and 2015, derived from lidar (Fig. 7a) and ECMWF data (Fig. 7b). For this, altitude profiles of GWED of all nights with at least $10 \mathrm{~h}$ of data were averaged. Comparing Figs. 6 and 7a, the data from 20/21 January 2015 are not unusual. Although the mean total GWED of January 2015 increases nearly throughout the altitude range (in contrast to the data of 20/21 January 2015), the increase is slightly steeper below $\approx 55 \mathrm{~km}$ altitude than it is above. The same is true for January 2014. In January 2012 the GWED between 40 and $60 \mathrm{~km}$ altitude is somewhat smaller than in January 2014 and 2015. The increase in total GWED with altitude exhibits a scale height of $\approx 16 \mathrm{~km}$. This is 2.3 times larger than the pressure scale height of $7 \mathrm{~km}$, a relation previously obtained by Fritts and VanZandt (1993) by posing a model gravity wave spectrum. The same scale height was found by Kaifler et al. (2015), although they observed potential energy densities only. Similar scale heights for total energy density and potential energy density would imply a kinetic-to-potential GWED ratio constant with altitude. However, our observations show that the kinetic-to-potential GWED ratio is typically between 5 and 10 and slightly increases with altitude, as can be seen in the right panel of Fig. 7a. When comparing absolute values of GWED to previous studies, it is necessary to keep in mind that GWEDs depend on season, locally different wave sources, and data analysis procedures (e.g., Baumgarten et al., 2017). Nevertheless, studies by Alexander et al. (2011) and Mzé et al. (2014) at Antarctic and midlatitude stations, respectively, found quantitatively similar results for potential GWEDs averaged over multiple years. Comparing data obtained at high-latitude stations is further affected by the position of the polar vortex, as shown by Whiteway et al. (1997).

Looking at mean GWEDs derived from ECMWF, below $45 \mathrm{~km}$ altitude they are of a similar order as the mean total GWEDs derived from lidar data. Above, the mean GWEDs derived from ECMWF are more or less constant with altitude, yielding an underestimation of GWED in ECMWF by a factor of 3-10. This is in line with the underestimated temporal temperature and wind speed variability found in Sect. 4.3.

\subsection{Larger-scale variations}

Applying the method to calculate energy densities not on $1 \mathrm{~h}$ profiles (as described in Sect. 3.2) but on all nightly mean temperature and wind speed profiles of 1 month yields energy densities on a larger timescale. Taking into account only nights with at least $10 \mathrm{~h}$ of observations largely reduces the effect of gravity waves and highlights the contribution from planetary waves or diurnal tides. It has to be noted that applying Eq. (1) to such large-scale variations assumes vertical displacements to be adiabatic and periodic, and advection is neglected. Analogously to the term gravity wave energy density, we will use the term large-scale wave energy den-
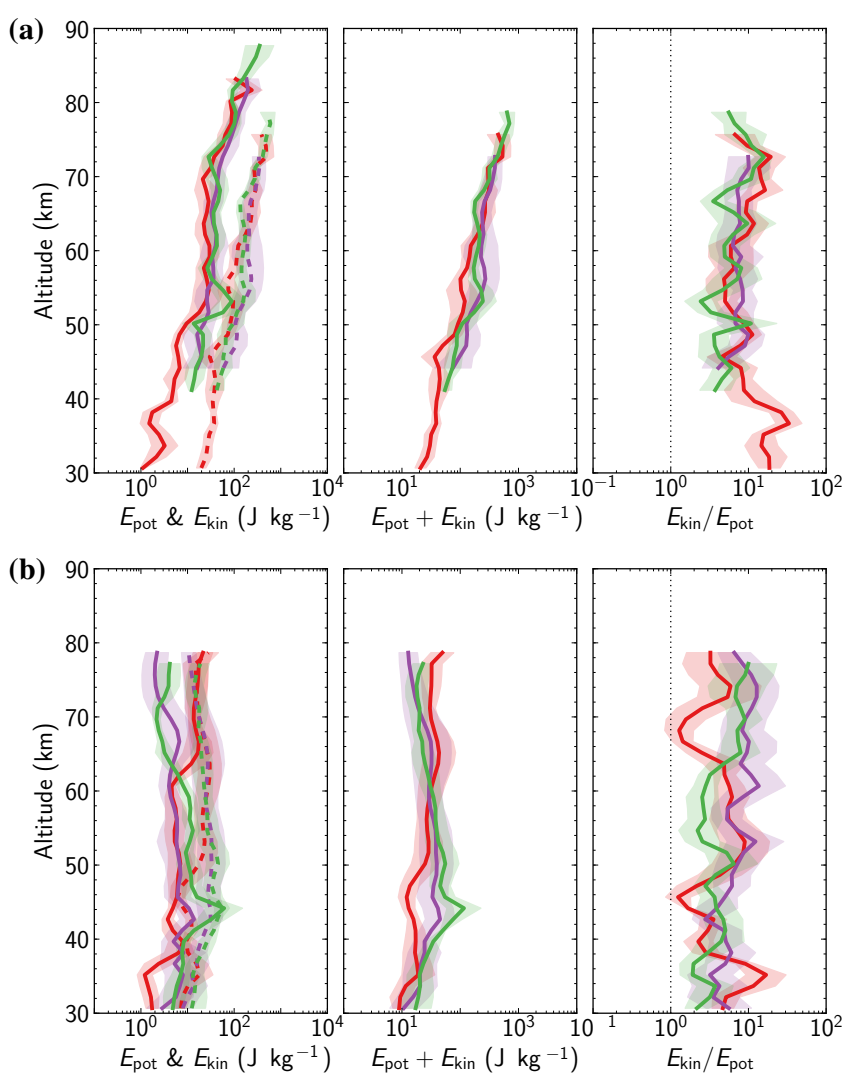

Figure 7. January mean gravity wave energy densities for 2012 (red), 2014 (purple), and 2015 (green) derived from lidar data (a) and ECMWF data (b). Shading represents the corresponding SD. Left: potential (solid) and kinetic (dashed) GWED. Middle: total GWED. Right: kinetic-to-potential GWED.

sity (LWED) to denote the so derived energy densities. The results for January 2012, January 2014, and January 2015 are shown in Fig. 8 for lidar data (Fig. 8a) and ECMWF data (Fig. 8b).

Compared to GWED, potential and kinetic LWEDs are more variable with altitude, and it occurs more often that potential LWED is larger than kinetic LWED. Therefore, kinetic-to-potential LWED ratios vary over more than 2 orders of magnitude. Although total LWEDs show distinct vertical variations, the overall increase with altitude is rather small: it slightly increases in January 2012 (with a local maximum around $70 \mathrm{~km}$ altitude) and January 2014 and slightly decreases in January 2015 with a local maximum around $60 \mathrm{~km}$ altitude.

Contrary to GWED, total LWED derived from ECMWF data is roughly on the same order of magnitude as the total LWED obtained from lidar data, not only in the lower part but in the entire altitude range; e.g., at $61 \mathrm{~km}$ altitude, mean total LWEDs range from $\approx 2.2 \times 10^{2}$ to $\approx 7.3 \times 10^{2} \mathrm{~J} \mathrm{~kg}^{-1}$ for the lidar data and from $\approx 1.7 \times 10^{2}$ to $\approx 2.4 \times 10^{2} \mathrm{~J} \mathrm{~kg}^{-1}$ for the ECMWF data. The kinetic-to-potential energy ratio is larger for the ECMWF data compared to lidar data, es- 
(a)
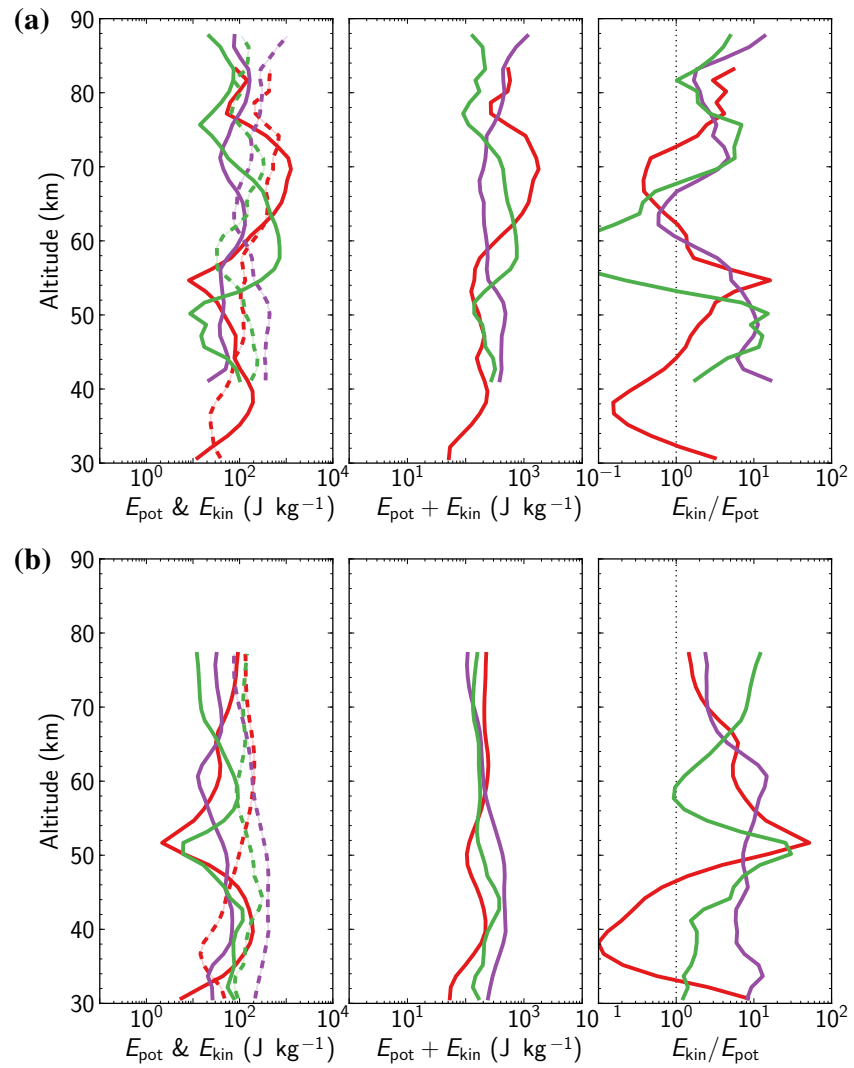

Figure 8. January energy densities per unit mass for large-scale waves for 2012 (red), 2014 (purple), and 2015 (green) derived from lidar data (a) and ECMWF data (b); see text for details. Left: potential (solid) and kinetic (dashed) LWEDs. Middle: total LWED. Right: kinetic-to-potential LWED.

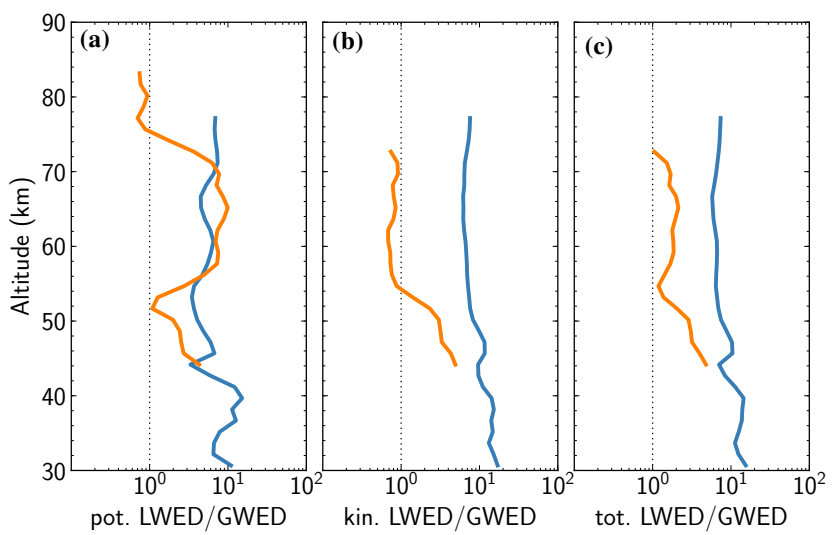

Figure 9. Mean LWED-to-GWED ratios for lidar data (orange) and ECMWF data (blue). Panel (a) potential energy densities. Panel (b) kinetic energy densities. Panel (c) total energy densities.

pecially above $55 \mathrm{~km}$ altitude. The explanation is that while the kinetic LWEDs derived from lidar data and ECMWF data are on the same order, the potential LWEDs derived from ECMWF data are smaller than derived from lidar data.
Hence, the day-to-day variability in temperatures in ECMWF is too weak, which is visible in Fig. 2 for January 2012.

Comparison of GWED and LWED profiles shows that LWEDs are mainly on the same order of magnitude as GWEDs. Increased mean LWED-to-GWED ratios (up to 10) occur between 60 and $70 \mathrm{~km}$ altitude and below $50 \mathrm{~km}$ altitude for potential energy densities and below $50 \mathrm{~km}$ altitude for kinetic energy densities, as is shown in Fig. 9. The total LWED is about 2 to 6 times larger than the total GWED.

\section{Summary and conclusions}

We presented results of more than $300 \mathrm{~h}$ of simultaneous temperature and wind observations by Doppler lidar in the Arctic stratosphere and mesosphere, ranging from 30 up to about $85 \mathrm{~km}$ altitude, obtained during Januaries 2012, 2014, and 2015.

Considering only these 3 years, large variability in the mean temperatures and horizontal winds is observed. The temperature and wind data were affected by large-scale dynamics in the middle atmosphere, e.g., an SSW in January 2012. After this minor SSW, two phenomena that are commonly linked to major SSWs (in particular polar vortex split events) were observed by the ALOMAR RMR lidar: an elevated stratopause and the reformation of the polar vortex. This large-scale activity can be seen for example in the LWED for January 2012 at about $70 \mathrm{~km}$ altitude when comparing to altitudes below or Januaries 2014 and 2015.

We compared mean temperatures and winds from lidar observations to ECMWF and HWM07 data, where we used model data only at times of the lidar observations. Below $\approx 55 \mathrm{~km}$ altitude, monthly mean zonal and meridional winds derived from lidar observations and extracted from ECMWF model data agree very well, with differences smaller than 2 and $5 \mathrm{~m} \mathrm{~s}^{-1}$, respectively. Above, we found differences of up to $20 \mathrm{~K}, 20$, and $5 \mathrm{~m} \mathrm{~s}^{-1}$ for monthly mean profiles of temperature, zonal, and meridional wind, respectively, between lidar and ECMWF data and of up to $30 \mathrm{~m} \mathrm{~s}^{-1}$ between lidar and HWM07 data.

Analysis of monthly mean gravity wave energy densities showed an increase in total GWED per unit mass with altitude with a scale height of $\approx 16 \mathrm{~km}$, which agrees with previously published values. For one sample night we investigated the ratio of kinetic to potential GWED and found that it varies remarkably with altitude. These variations might be caused by diverse origins of the waves or changing background conditions for wave propagation. Comparison with ECMWF data shows that GWEDs are underestimated in ECMWF by a factor of 3-10 above $50 \mathrm{~km}$ altitude. Analyzing fluctuations of nightly mean profiles allows a similar study for large-scale waves instead of gravity waves. Compared to GWEDs, the LWEDs show larger vertical variations, but the overall increase with altitude is smaller. Contrary to GWEDs, the kinetic-to-potential LWED ratios might become 
smaller than 1 , this indicates more variability in temperature than in wind, which applies for the remarkable temperature changes in January 2012 at 40 and $70 \mathrm{~km}$ altitude in the course of the SSW (cf. Fig. 2). Likewise, a ratio larger than 1 indicates larger wind speed variability, e.g., in January 2014 and January 2015 around $50 \mathrm{~km}$ altitude, when the stratopause temperature is quite stable, while wind speeds vary strongly (they are affected sensitively by the shape and position of the polar vortex). Total LWEDs derived from ECMWF data agree reasonably well with LWEDs derived from lidar data: e.g., at $61 \mathrm{~km}$ altitude the mean LWEDs derived from lidar and ECMWF data are $\approx 4.5 \times 10^{2}$ and $\approx 2.0 \times 10^{2} \mathrm{~J} \mathrm{~kg}^{-1}$, respectively. LWEDs are mainly on the same order of magnitude as GWEDs. At altitudes of enhanced large-scale variations, namely between 60 and $70 \mathrm{~km}$ altitude for temperatures and below $50 \mathrm{~km}$ altitude for winds, they exceed GWEDs by up to 10 . The total LWED is about 2 to 5 times larger than the total GWED.

In future studies, daylight data will be included, which will allow us to capture tidal effects and extend the analyses to other seasons.

Data availability. Data are available at ftp://ftp.iap-kborn.de/ data-in-publications/HildebrandACP2017/.

Competing interests. The authors declare that they have no conflict of interest.

Acknowledgements. This study benefited from the excellent support by the dedicated staff at the ALOMAR observatory and the voluntary lidar operators during winter campaigns. The European Centre for Medium-Range Weather Forecasts (ECMWF) is gratefully acknowledged for providing the forecast data; cycles Cy37r3 and Cy40r1 were used in this study. The DoRIS project was supported by Deutsche Forschungsgemeinschaft (DFG, German Research Foundation, no. BA 2834/1-1). This project has received funding from the European Union's Horizon 2020 Research and Innovation programme under grant agreement no. 653980 (ARISE2) and was supported by the Deutsche Forschungsgemeinschaft (DFG, German Research Foundation) under project no. LU 1174 (PACOG) and by the German Federal Ministry of Education and Research through the program Role Of The Middle atmosphere In Climate (ROMIC). The publication of this article was funded by the Open Access Fund of the Leibniz Association.

Edited by: Matthias Tesche

Reviewed by: Jonathan Friedman and two anonymous referees

\section{References}

Alexander, S. P., Klekociuk, A. R., and Murphy, D. J.: Rayleigh lidar observations of gravity wave activity in the winter upper stratosphere and lower mesosphere above
Davis, Antarctica $\left(69^{\circ} \mathrm{S}, 78^{\circ} \mathrm{E}\right)$, J. Geophys. Res., 116, 1-1, https://doi.org/10.1029/2010JD015164, 2011.

Assink, J. D., Waxler, R., and Drob, D.: On the sensitivity of infrasonic traveltimes in the equatorial region to the atmospheric tides, J. Geophys. Res., 117, d01110, https://doi.org/10.1029/2011JD016107, 2012.

Baron, P., Murtagh, D. P., Urban, J., Sagawa, H., Ochiai, S., Kasai, Y., Kikuchi, K., Khosrawi, F., Körnich, H., Mizobuchi, S., Sagi, K., and Yasui, M.: Observation of horizontal winds in the middle-atmosphere between $30^{\circ} \mathrm{S}$ and $55^{\circ} \mathrm{N}$ during the northern winter 2009-2010, Atmos. Chem. Phys., 13, 6049-6064, https://doi.org/10.5194/acp-13-6049-2013, 2013.

Baumgarten, G.: Doppler Rayleigh/Mie/Raman lidar for wind and temperature measurements in the middle atmosphere up to $80 \mathrm{~km}$, Atmos. Meas. Tech., 3, 1509-1518, https://doi.org/10.5194/amt-3-1509-2010, 2010.

Baumgarten, G., Fiedler, J., Hildebrand, J., and Lübken, F.-J.: Inertia gravity wave in the stratosphere and mesosphere observed by Doppler wind and temperature lidar, Geophys. Res. Lett., 42, 10929-10936, https://doi.org/10.1002/2015GL066991, 2015.

Baumgarten, K., Gerding, M., and Lübken, F.-J.: Seasonal variation of gravity wave parameters using different filter methods with daylight lidar measurements at mid-latitudes, J. Geophys. Res., 122, 2683-2695, https://doi.org/10.1002/2016JD025916, 2017.

Bossert, K., Fritts, D. C., Pautet, P.-D., Taylor, M. J., Williams, B. P., and Pendelton, W. R.: Investigation of a mesospheric gravity wave ducting event using coordinated sodium lidar and mesospheric temperature mapper measurements at ALOMAR, Norway $\left(69^{\circ} \mathrm{N}\right)$, J. Geophys. Res., 119, 9765-9778, https://doi.org/10.1002/2014JD021460, 2014.

Chandran, A., Collins, R. L., Garcia, R. R., Marsh, D. R., Harvey, V. L., Yue, J., and de la Torre, L.: A climatology of elevated stratopause events in the whole atmosphere community climate model, J. Geophys. Res., 118, 1234-1246, https://doi.org/10.1002/jgrd.50123, 2013a.

Chandran, A., Garcia, R. R., Collins, R. L., and Chang, L. C.: Secondary planetary waves in the middle and upper atmosphere following the stratospheric sudden warming event of January 2012, Geophys. Res. Lett., 40, 1861-1867, https://doi.org/10.1002/grl.50373, 2013b.

Chanin, M. L. and Hauchecorne, A.: Lidar Observation of Gravity and tidal Waves in the Stratosphere and Mesosphere, Geophys. Res. Lett., 86, 9715-9721, 1981.

Dörnbrack, A., Gisinger, S., and Kaifler, B.: On the interpretation of gravity wave measurements by ground-based lidars, Atmosphere, 8, 49, https://doi.org/10.3390/atmos8030049, 2017.

Drob, D. P., Emmert, J. T., Crowley, G., Picone, J. M., Shepherd, G. G., Skinner, W., Hays, P., Niciejewski, R. J., Larsen, M., She, C.-Y., Meriwether, J. W., Hernandez, G., Jarvis, M. J., Sipler, D. P., Tepley, C. A., O’Brien, M. S., Bowman, J. R., Wu, Q., Murayama, Y., Kawamura, S., Reid, I. M., and Vincent, R. A.: An empirical model of the Earth's horizontal wind fields: HWM07, J. Geophys. Res., 113, A12, https://doi.org/10.1029/2008JA013668, 2008.

Eckermann, S. D., Hirota, I., and Hocking, W. K.: Gravity wave and equatorial wave morphology of the stratosphere derived from long-term rocket soundings, Q. J. Roy. Meteor. Soc., 121, 149186, https://doi.org/10.1002/qj.49712152108, 1995. 
Ehard, B., Kaifler, B., Kaifler, N., and Rapp, M.: Evaluation of methods for gravity wave extraction from middle-atmospheric lidar temperature measurements, Atmos. Meas. Tech., 8, 46454655, https://doi.org/10.5194/amt-8-4645-2015, 2015.

Fee, D., Waxler, R., Assink, J., Gitterman, Y., Given, J., Coyne, J., Mialle, P., Garces, M., Drob, D., Kleinert, D., Hofstetter, R., and Grenard, P.: Overview of the 2009 and 2011 Sayarim Infrasound Calibration Experiments, J. Geophys. Res., 118, 61226143, https://doi.org/10.1002/jgrd.50398, 2013.

Franke, S. J., Chu, X., Liu, A. Z., and Hocking, W. K.: Comparison of meteor radar and $\mathrm{Na}$ Doppler lidar measurements of winds in the mesopause region above Maui, Hawaii, J. Geophys. Res., 110, D09S02, https://doi.org/10.1029/2003JD004486, 2005.

Friedman, J. S., Tepley, C. A., Castleberg, P. A., and Roe, H.: Middle-atmospheric Doppler lidar using an iodine-vapor edge filter, Opt. Lett., 22, 1648-1650, 1997.

Fritts, D. C. and Alexander, M. J.: Gravity wave dynamics and effects in the middle atmosphere, Rev. Geophys., 41, 1003, https://doi.org/10.1029/2001RG000106, 2003.

Fritts, D. C. and VanZandt, T. E.: Spectral estimates of gravity wave evergy and momentum fluxes, Part I: Energy dissipation, acceleration, and constraints., J. Atmos. Sci., 50, 3685-3694, https://doi.org/10.1175/15200469(1993)050<3685:SEOGWE>2.0.CO;2, 1993.

Geller, M. A.: Dynamics of the middle atmosphere, Space Sci. Rev., 34, 359-375, 1983.

Geller, M. A. and Gong, J.: Gravity wave kinetic, potential, and vertical fluctuation energies as indicators of different frequency gravity waves, J. Geophys. Res., 115, D11, https://doi.org/10.1029/2009JD012266, 2010.

Gill, A. E.: Atmosphere-Ocean Dynamics, International Geophysics Series, 30, Academic Press, New York, 1982.

Goldberg, R. A., Fritts, D. C., Williams, B. P., Lübken, F.J., Rapp, M., Singer, W., Latteck, R., Hoffmann, P., Müllemann, A., Baumgarten, G., Schmidlin, F. J., She, C.-Y., and Krueger, D. A.: The MaCWAVE/MIDAS rocket and groundbased measurements of polar summer dynamics: Overview and mean state structure, Geophys. Res. Lett., 31, 124S02, https://doi.org/10.1029/2004GL019411, 2004.

Hauchecorne, A. and Chanin, M.-L.: Density and temperature profiles obtained by lidar between 35 and $70 \mathrm{~km}$, Geophys. Res. Lett., 7, 565-568, https://doi.org/10.1029/GL007i008p00565, 1980.

Hays, P. B., Abreu, V. J., Dobbs, M. E., Gell, D. A., Grassl, H. J., and Skinner, W. R.: The high-resolution Doppler imager on the upper atmosphere research satellite, J. Geophys. Res., 981, 10713, https://doi.org/10.1029/93JD00409, 1993.

Hedlin, M. A. H. and Walker, K. T.: A study of infrasonic anisotropy and multipathing in the atmosphere using seismic networks, Philos. T. Roy. Soc. A, 371, 1984, https://doi.org/10.1098/rsta.2011.0542, 2012.

Hildebrand, J., Baumgarten, G., Fiedler, J., Hoppe, U.-P., Kaifler, B., Lübken, F.-J., and Williams, B. P.: Combined wind measurements by two different lidar instruments in the Arctic middle atmosphere, Atmos. Meas. Tech., 5, 2433-2445, https://doi.org/10.5194/amt-5-2433-2012, 2012.

Holton, J. R.: The influence of gravity wave breaking on the general circulation of the middle atmosphere, J. At- mos. Sci., 40, 2497-2507, https://doi.org/10.1175/15200469(1983)040<2497:TIOGWB>2.0.CO;2, 1983.

Huang, W., Chu, X., Williams, B. P., Harrell, S. D., Wiig, J., and She, C.-Y.: Na double-edge magneto-optic filter for Na lidar profiling of wind and temperature in the lower atmosphere, Opt. Lett., 34, 199-201, https://doi.org/10.1364/OL.34.000199, 2009.

Jablonowski, C. and Williamson, D. L.: The Pros and Cons of Diffusion, Filters and Fixers in Atmospheric General Circulation Models, Springer, Berlin, Heidelberg, 381-493, 2011.

Kaifler, B., Kaifler, N., Ehard, B., Dörnbrack, A., Rapp, M., and Fritts, D. C.: Influences of source conditions on mountain wave penetration into the stratosphere and mesosphere, Geophys. Res. Lett., 42, 9488-9494, https://doi.org/10.1002/2015GL066465, 2015.

Kent, G. S. and Wright, R. W. H.: A review of laser radar measurements of atmospheric properties, J. Atmos. Terr. Phys., 32, 917-943, 1970.

Killeen, T. L., Wu, Q., Solomon, S. C., Ortland, D. A., Skinner, W. R., Niciejewski, R. J., and Gell, D. A.: TIMED Doppler interferometer: overview and recent results, J. Geophys. Res., 111, A10S01, https://doi.org/10.1029/2005JA011484, 2006.

Kristoffersen, S. K., Ward, W. E., Brown, S., and Drummond, J. R.: Calibration and validation of the advanced E-Region Wind Interferometer, Atmos. Meas. Tech., 6, 1761-1776, https://doi.org/10.5194/amt-6-1761-2013, 2013.

Labitzke, K.: Temperature changes in the mesosphere and stratosphere connected with circulation changes in winter, J. Atmos. Sci., 29, 756-766, 1972.

Labitzke, K. and Kunze, M.: Interannual variability and trends in the stratosphere, in: Climate and Weather of the Sun-Earth System (CAWSES): Highlights from a Priority Program, edited by: Lübken, F.-J., Springer, Dordrecht, the Netherlands, 573-584, 2012.

Lane, T. P., Reeder, M. J., and Guest, F. M.: Convectively generated gravity waves observed from radiosonde data taken during MCTEX, Q. J. Roy. Meteorol. Soc., 129, 1731-1740, https://doi.org/10.1256/qj.02.196, 2003.

Le Pichon, A., Assink, J. D., Heinrich, P., Blanc, E., CharltonPerez, A., Lee, C. F., Keckhut, P., Hauchecorne, A., Rüfenacht, R., Kämpfer, N., Drob, D. P., Smets, P. S. M., Evers, L. G., Ceranna, L., Pilger, C., Ross, O., and Claud, C.: Comparison of co-located independent ground-based middle atmospheric wind and temperature measurements with numerical weather prediction models, J. Geophys. Res., 120, 8318-8331, https://doi.org/10.1002/2015JD023273, 2015.

Lindzen, R. S.: Turbulence and stress owing to gravity wave and tidal breakdown, J. Geophys. Res., 86, 9707-9714, 1981.

Liu, A. Z., Hocking, W. K., Franke, S. J., and Thayaparan, T.: Comparison of $\mathrm{Na}$ lidar and meteor radar wind measurements at Starfire Optical Range, NM, USA, J. Atmos. Sol.-Terr. Phy., 64, 31-40, https://doi.org/10.1016/S1364-6826(01)00095-5, 2002.

Lübken, F.-J. and Müllemann, A.: Temperatures, densities, and winds in the high latitude $\left(78^{\circ} \mathrm{N}\right)$ mesosphere, Adv. Space Res., 32, 731-740, https://doi.org/10.1016/S0273-1177(03)00408-3, 2003.

Lübken, F.-J., Baumgarten, G., Hildebrand, J., and Schmidlin, F. J.: Simultaneous and co-located wind measurements in the middle atmosphere by lidar and rocket-borne techniques, Atmos. Meas. 
Tech., 9, 3911-3919, https://doi.org/10.5194/amt-9-3911-2016, 2016.

Manney, G. L., Schwartz, M. J., Krüger, K., Santee, M. L., Pawson, S., Lee, J. N., Daffer, W. H., Fuller, R. A., and Livesey, N. J.: Aura microwave limb sounder observations of dynamics and transport during the record-breaking 2009 Arctic stratospheric major warming, Geophys. Res. Lett., 36, L12815, https://doi.org/10.1029/2009GL038586, 2009.

Matsuno, T.: A dynamical model of the stratospheric sudden warming, J. Atmos. Sci., 28, 1479-1494, 1971.

Matthias, V., Hoffmann, P., Manson, A., Meek, C., Stober, G., Brown, P., and Rapp, M.: The impact of planetary waves on the latitudinal displacement of sudden stratospheric warmings, Ann. Geophys., 31, 1397-1415, https://doi.org/10.5194/angeo31-1397-2013, 2013.

Meriwether, J. W. and Gerrard, A. J.: Mesosphere inversion layers and stratosphere temperature enhancements, Rev. Geophys., 42, RG3003, https://doi.org/10.1029/2003RG000133, 2004.

Meyer, W., Philbrick, C. R., Röttger, J., Rüster, R., Widdel, H.-U., and Schmidlin, F. J.: Mean winds in the winter middle atmosphere above northern Scandinavia, J. Atmos. Terr. Phys., 49, 675-687, https://doi.org/10.1016/0021-9169(87)90012-2, 1987.

Müllemann, A. and Lübken, F.-J.: Horizontal winds in the mesosphere at high latitudes, Adv. Space Res., 35, 1890-1894, 2005.

Mzé, N., Hauchecorne, A., Keckhut, P., and Thétis, M.: Vertical distribution of gravity wave potential energy from long-term Rayleigh lidar data at a northern middlelatitude site, J. Geophys. Res., 119, 12069-12083, https://doi.org/10.1002/2014JD022035, 2014.

Nappo, C. J.: An introduction to atmospheric gravity waves, Academic Press, Amsterdam, 2002.

Placke, M., Hoffmann, P., Gerding, M., Becker, E., and Rapp, M.: Testing linear gravity wave theory with simultaneous wind and temperature data from the mesosphere, J. Atmos. Solar-Terr. Phys., 93, 57-69, https://doi.org/10.1016/j.jastp.2012.11.012, 2013.

Randel, W. J.: The evaluation of winds from geopotential height data in the stratosphere, J. Atmos. Sci., 44, 3097-3120, 1987.

Rex, M., von der Gathen, P., Harris, N. R. P., Lucic, D., Knudsen, B. M., Braathen, G. O., Reid, S. J., De Backer, H., Claude, H., Fabian, R., Fast, H., Gil, M., Kyrö, E., Mikkelsen, I. S., Rummukainen, M., Smit, H. G., Stähelin, J., Varotsos, C., and Zaitcev, I.: In situ measurements of stratospheric ozone depletion rates in the Arctic winter 1991/1992: a lagrangian approach, J. Geophys. Res., 103, 5843-5853, https://doi.org/10.1029/97JD03127, 1998.

Rüfenacht, R., Kämpfer, N., and Murk, A.: First middleatmospheric zonal wind profile measurements with a new ground-based microwave Doppler-spectro-radiometer, Atmos. Meas. Tech., 5, 2647-2659, https://doi.org/10.5194/amt-5-26472012, 2012.

Rüfenacht, R., Murk, A., Kämpfer, N., Eriksson, P., and Buehler, S. A.: Middle-atmospheric zonal and meridional wind profiles from polar, tropical and midlatitudes with the ground-based microwave Doppler wind radiometer WIRA, Atmos. Meas. Tech., 7, 4491-4505, https://doi.org/10.5194/amt-7-4491-2014, 2014.

Schmidlin, F. J., Lee, H., and Michel, W.: The inflatable sphere: a technique for the accurate measurement of middle at- mosphere temperatures, J. Geophys. Res., 96, 22673-22682, https://doi.org/10.1029/91JD02395, 1991.

Schöch, A., Baumgarten, G., and Fiedler, J.: Polar middle atmosphere temperature climatology from Rayleigh lidar measurements at ALOMAR (69 $\mathrm{N})$, Ann. Geophys., 26, 1681-1698, https://doi.org/10.5194/angeo-26-1681-2008, 2008.

Schroeder, S., Preusse, P., Ern, M., and Riese, M.: Gravity waves resolved in ECMWF and measured by SABER, Geophys. Res. Lett., 36, 110805, https://doi.org/10.1029/2008GL037054, 2009.

She, C.-Y., Vance, J. D., Williams, B. P., Krueger, D. A., Moosmuller, H., Gibson-Wilde, D., and Fritts, D.: Lidar studies of atmospheric dynamics near polar mesopause, Eos T. Am. Geophys. Un., 83, 289, 27, https://doi.org/10.1029/2002EO000206, 2002.

Shepherd, G. G., Thuillier, G., Gault, W. A., Solheim, B. H., Hersom, C., Alunni, J. M., Brun, J.-F., Brune, S., Charlot, P., and Cogger, L. L.: WINDII, the wind imaging interferometer on the upper atmosphere research satellite, J. Geophys. Res., 981, 10725, https://doi.org/10.1029/93JD00227, 1993.

Souprayen, C., Garnier, A., Hertzog, A., Hauchecorne, A., and Porteneuve, J.: Rayleigh-Mie Doppler wind lidar for atmospheric measurements. I: Instrumental setup, validation, and first climatological results, Appl. Optics, 38, 2410-2421, https://doi.org/10.1364/AO.38.002410, 1999.

Tepley, C. A.: Neutral winds of the middle atmosphere observed at Arecibo using a Doppler Rayleigh lidar, J. Geophys. Res., 99, 25781-25790, https://doi.org/10.1029/94JD02213, 1994.

Tomikawa, Y., Sato, K., Watanabe, S., Kawatani, Y., Miyazaki, K., and Takahashi, M.: Growth of planetary waves and the formation of an elevated stratopause after a major stratospheric sudden warming in a T213L256 GCM, J. Geophys. Res., 117, d16101, https://doi.org/10.1029/2011JD017243, 2012.

de la Torre, L., Garcia, R. R., Barriopedro, D., and Chandran, A.: Climatology and characteristics of stratospheric sudden warmings in the Whole Atmosphere Community Climate Model, J. Geophys. Res., 117, D04110, https://doi.org/10.1029/2011JD016840, 2012.

Whiteway, J. A. and Carswell, A. I.: Lidar observations of gravity wave activity in the upper stratosphere over Toronto, J. Geophys. Res., 100, 14113-14124, https://doi.org/10.1029/95JD00511, 1995.

Whiteway, J. A., Duck, T. J., Donovan, D. P., Bird, J. C., Pal, S. R., and Carswell, A. I.: Measurements of gravity wave activity within and around the Arctic stratospheric vortex, Geophys. Res. Lett., 24, 1387-1390, https://doi.org/10.1029/97GL01322, 1997.

Widdel, H.-U.: Vertical movements in the middle atmosphere derived from foil cloud experiments, J. Atmos. Terr. Phys., 49, 723741, https://doi.org/10.1016/0021-9169(87)90015-8, 1987.

Widdel, H.-U.: Foil chaff clouds as a tool for in-situ measurements of atmospheric motions in the middle atmosphere: Their flight behaviour and implications for radar tracking, J. Atmos. Terr. Phys., 52, 89-101, https://doi.org/10.1016/00219169(90)90071-T, 1990.

Wu, D. L., Schwartz, M. J., Waters, J. W., Limpasuvan, V., Wu, Q., and Killeen, T. L.: Mesospheric Doppler wind measurements from Aura Microwave Limb Sounder (MLS), Adv. Space Res., 42, 1246-1252, https://doi.org/10.1016/j.asr.2007.06.014, 2008. 
Xia, H., Dou, X., Sun, D., Shu, Z., Xue, X., Han, Y., Hu, D., Han, Y., and Cheng, T.: Mid-altitude wind measurements with mobile Rayleigh Doppler lidar incorporating system-level optical frequency control method, Opt. Express, 20, 15286-15300, https://doi.org/10.1364/OE.20.015286, 2012.

Yuan, T., Thurairajah, B., She, C.-Y., Chandran, A., Collins, R. L., and Krueger, D. A.: Wind and temperature response of midlatitude mesopause region to the 2009 Sudden Stratospheric Warming, J. Geophys. Res., 117, D09114, https://doi.org/10.1029/2011JD017142, 2012. von Zahn, U., von Cossart, G., Fiedler, J., Fricke, K. H., Nelke, G., Baumgarten, G., Rees, D., Hauchecorne, A., and Adolfsen, K.: The ALOMAR Rayleigh/Mie/Raman lidar: objectives, configuration, and performance, Ann. Geophys., 18, 815-833, https://doi.org/10.1007/s00585-000-0815-2, 2000.

Zink, F. and Vincent, R.: Wavelet analysis of stratosphere gravity wave packets over Macquarie Island 1. wave parameters, J. Geophys. Res., 106, D10, https://doi.org/10.1029/2000JD900847, 2001. 